\title{
Chrysin Alleviates DNA Damage to Improve Disturbed Immuno-Homeostasis and Pro- Angiogenic Environment in Laser-Induced Choroidal Neovascularization
}

\author{
Jing Wang \\ Shanghai General Hospital https://orcid.org/0000-0003-4477-9442 \\ Qiyu Bo \\ Shanghai General Hospital Department of Ophthalmology \\ Minwen Zhou \\ Shanghai General Hospital Department of Ophthalmology \\ Hong Wang \\ Shanghai General Hospital Department of Ophthalmology \\ Hong Zhu \\ Shanghai General Hospital Department of Ophthalmology \\ Fenghua Wang \\ Shanghai General Hospital Department of Ophthalmology \\ Mei Jiang \\ Shanghai General Hospital Department of Ophthalmology \\ Xiaodong Sun ( $\nabla$ xdsun@sjtu.edu.cn ) \\ Shanghai General Hospital Department of Ophthalmology
}

\section{Research}

Keywords: Choroidal neovascularization, DNA damage, RPE dysfunction, inflammation, angiogenesis, chrysin

Posted Date: August 31st, 2021

DOl: https://doi.org/10.21203/rs.3.rs-827729/v1

License: (1) This work is licensed under a Creative Commons Attribution 4.0 International License. Read Full License 


\section{Abstract}

Background: Choroidal neovascularization (CNV) is a devastating pathology of numerous ocular diseases, such as wet age-related macular degeneration (wAMD), which causes irreversible vision loss. Although anti-VEGF therapy has been widely used, poor response or no response exits in some patients, suggesting that some other important angiogenic components play roles. Therefore, the underlined mechanism need to be clarified and new target of anti-angiogenic therapy is urgently needed. Damaged retinal pigment epithelium (RPE) cells have been demonstrated to activate inflammasome, drive a degenerative tissue environment and an enhanced pro-angiogenic response, which emphasizes the dysfunction of RPE, may be the hallmark of the pathogenesis.

Methods: C57BL/6J male mice aged between 6 and 8 weeks were subjected to laser-induced CNV models. Chrysin was administered intragastrically at $25 \mathrm{mg} / \mathrm{kg}$ daily for 3 days or one week after lasertreated. Then to observe the CNV areas and CNV thickness, immunofluorescence staining of choroidal flatmount, SD-OCT and fluorescein angiograghy were performed, respectively. To further confirm the effect of chrysin on stress-induced DNA damage in RPE cells, RPE cells were administered with A2E and western-blot, cell viability assay, immunofluorescence chromosome PNA-FISH and SA- $\beta$-gal staining were performed. To elucidate the underlying mechanism, we performed RNA-seq and bioinformatics analyses.

Results: In this study, we demonstrated that chrysin could successfully alleviated choroidal neovascularization. We show that DNA damage of RPE cells is remarkable in laser-induced choroidal neovascularization, resulting in inflammation response, which can be ameliorated by chrysin through inactivation of STAT3. Also, we identify that chrysin can reduce DNA damage, especially telomere erosion, simultaneously compromise the dysfunction of RPE and the secretion of SASP factor in vitro. Mechanistically, KEGG pathway analyzes show that chrsyin improves inflammatory imbalance mainly through down-regulation of IL17 pathway in the laser- induced CNV development.

Conclusions: Our results indicate the interplay between DNA damage, perturbed RPE homeostasis, inflammatory imbalance and angiogenesis in laser-induced choroidal neovascularization. Importantly, chrysin may be an effective therapeutic supplement for CNV.

\section{Background}

Choroidal neovascularization (CNV) is the hallmark of numerous ocular diseases, such as wet age-related macular degeneration (WAMD), which is the major cause of vision impairment among elderly population in developed countries. The etiology of CNV is believed to be multifactorial and remains unclear. Intravitreal injection of anti-VEGF agents, which is the first-line therapy for CNV treatment, has achieved great success in suppressing pathological angiogenesis and improving vision. However, the beneficial effect of anti-VEGF therapy begins to wear off and a substantial number of patient revealed poor response or no response to anti-VEGF therapy[1, 2], suggesting other proangiogenic mechanisms may play roles and need to be elucidated urgently. 
Inflammation has been demonstrated to play critical role in AMD and even pathological angiogenesis. In retina, RPE cells contribute to immune privilege, which can modulate innate and adaptive immunity [3]. RPE dysfunction is considered to be the primary cause of pro-inflammatory environment. It has been found that RPE destruction in the model of laser-induced CNV polarizes infiltrating myeloid cells toward a pro-angiogenic phenotype[4]. And dysfunctional RPE modulates macrophage responses, driving further cell death and promoting angiogenesis in the eye [5]. These evidences suggest the crosstalk between RPE dysfunction and disturbed immuno-homeostasis in CNV.

DNA damage is a common cause of retinal diseases. Long-term sunlight exposure, especially UV irradiation, could significantly induce DNA damage in the retina [6, 7]. One study has demonstrated that 8OHdG level induced by DNA damage in aqueous humor was significantly higher in AMD patients and correlated with neovascular lesion size, which suggests that DNA damage is associated with CNV [8]. Previously, we have demonstrated that DNA damage, including telomere deprotection, can accelerate RPE dysfunction, triggering inflammatory environment [9]. Thus, in present study, we wonder whether DNA damage was present in the acute destruction of RPE, further driving inflammatory environment, which contribute to CNV development. Results of this study will elucidate the potential crosstalk between DNA damage, perturbed RPE homeostasis, inflammation and angiogenesis, which help to identify supplementary targets for CNV treatment strategies.

Chrysin (5, 7-dihydroxyflavone) is a member of the flavonoid family that is found in honey, propolis and many other plants [10]. Plenty of evidence shows that chrysin has broad spectrum of biological activities such as antitumor, immunomodulatory, anti-inflammatory, antioxidant and cardioprotective effects [11]. Recently, chrysin has been used to investigate the possibility of application in ocular disease. Intravitreally injected with chrysin successfully reduced the intensity of fluorescein leakage in laserinduced CNV lesion [12]. However, the mechanism is undiscovered. In present study, we demonstrated that chrysin could protect RPE cells from DNA damage, improve the disturbed immuno-homeostasis and pro-agiogenic environment, which effectively suppress CNV development. Results indicate that chrysin may be an effective therapeutic supplement for CNV and emphasize the critical role of interplay between DNA damage, RPE cell dysfunction, inflammation and angiogenesis in laser-induced CNV.

\section{Methods}

\section{Cell culture and animals}

Human adult RPE cells (APRE-19; American Type Culture Collection, Manassas, VA, USA) were cultured in Dulbecco`s modified Eagle's/Ham's F12 (Invitrogen, Grand Island, NY, USA) with 10\% fetal bovine serum (Invitrogen), $100 \mu \mathrm{g} / \mathrm{mL}$ streptomycin, and $100 \mathrm{U} / \mathrm{mL}$ penicillin at $37^{\circ} \mathrm{C}$ under $5 \% \mathrm{CO}_{2}$ and $95 \%$ humidified air.

Adult C57BL/6 mice (aged between 6-8 weeks old, weighed $20 \pm 1 \mathrm{~g}$ ) were used in this study. All animals were treated according to the guidelines of the ARVO statement for the Use of Animals in Ophthalmic and 
Vision Research. The experimental procedures were approved by the Institutional Animal Care and Use Committee of Shanghai Jiao Tong University (Shanghai, China). The mice were housed and maintained in the animal care services facility and subjected to a 12-hour light/dark cycle with constant access to nourishments. Chrysin (Sigma-Aldrich, C801052) was dissolved in dimethyl sulfoxide (DMSO); a final use concentration of DMSO was $<0.5 \%$.

\section{A2E formation and treatment}

A2E was synthesized as described previously.[27] RPE cells were incubated with A2E in culture medium for $24 \mathrm{~h}$ and washed three times to remove extracellular A2E. After A2E loading, RPE cells were exposed to $460 \pm 20 \mathrm{~nm}$ wavelength light (4000lx; Osram, Augsburg, Germany) for $20 \mathrm{~min}$, as described previously [27] .

\section{Laser-induced Mouse CNV model}

C57BL/6J male mice aged between 6 and 8 weeks and approximately $20 \mathrm{~g}$ were included. After application of tropicamide (Santen, Osaka, Japan) for pupil dilatation, animals were anesthetized with intraperitoneal injection of $1 \%$ pentobarbital sodium $(0.1 \mathrm{~mL} / 10 \mathrm{~g}$ body weight) (Guge Biotech, Wuhan, China). Covered with loxacin eye ointment (Xing Qi Pharmaceutical Companies, Shenyang, China), and four laser spots were distributed around the optic nerve head with an argon laser $(110 \mathrm{~mW}, 100 \mathrm{~ms}, 50 \mu \mathrm{m}$, OcuLight Infrared Laser System 810 nm, Iridex Corp., Mountain View, CA, USA). Appearance of a gray bubble indicative of the rupture of Bruch's membrane were included. If retinal bleeding occurred, the animal was eliminated. Eyes were enucleated at different time points.

\section{Perfusion fixation}

Mice were perfused transcardially with cold $4 \%$ paraformaldehyde. In brief, mice were administered with an over dose $(0.2 \mathrm{~mL})$ of $1 \%$ sodium pentobarbital and monitored until the point when the animal fails to respond to pinching of the foot. Incisions in the abdomen and diaphragm were made to expose the heart and perfusion needle was placed into ascending aorta. Cold $4 \%$ paraformaldehyde was poured into left ventricle of mouse through a peristaltic perfusion pump (Cole-Parmer Masterflex, NewYork, USA). Twitching of muscles suggests that the perfusion is proceeding properly. After the effluent runs clear, pump was stopped, eyes were harvested, post-fixed for two hours and then placed in PBS to make choroidal flatmounts or put into $30 \%$ sucrose solutions to make frozen sections.

\section{Choroidal flatmount and immunofluorescence staining}

After perfusion fixation and post-fixation, choroidal flatmounts were made under an operating microscope (Olympus, Tokyo, Japan). The cornea, lens and vitreous of a mouse eye were removed and the retina was separated from the choroid. Then the remaining RPE-choroid cup was cut four to six radial incisions to be flattened. Then the RPE-choroid complexes were blocked in $5 \%$ goat serum albumin with $0.3 \%$ Triton X-100 for one hour at room temperature, and were incubated with FITC-labeled isolectin-B4 (IB4) (FL-1201, Vector Laboratories, Burlingame, CA) and primary Abs FITC-labeled isolectin-B4 (IB4) (FL- 


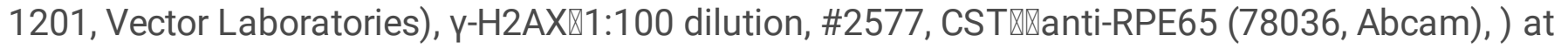
$4{ }^{\circ} \mathrm{C}$ overnight. The next day, RPE-choroid complexes were washed and incubated in appropriate secondary antibodies at room temperature for one hour. Secondary antibodies used were Alexa Fluor 488 and Alexa Fluor 594 (SA00003-11 and SA00006-4, Proteintech, Chicago, USA). At the end of the process, 4,6-diamidino-2-phenylindole (DAPI) (Vector Laboratories, Bu rlingame, CA) was used to counterstain the nucleus. Images were taken with a fluorescence microscope (Olympus, Tokyo, Japan) or a Leica TCS SP8 confocal laser scanning microscope (Leica TCS NT, Wetzlar, Germany).

\section{Fluorescence angiography}

FA was performed at day 7, after laser to observe the severity of CNV leakage. Firstly, mice were anesthetized with $1 \%$ sodium pentobarbital (Guge Biotech, Wuhan, China) i.p. at a volume of $5 \mu \mathrm{L} \cdot \mathrm{g}^{-1}$ body weight. Secondly, each mouse was injected intraperitoneally with $0.05 \mathrm{~mL}$ of $10 \%$ fluorescein sodium (Fluorescite; Alcon, Tokyo, Japan), and fundus angiogram photos were captured at the middle stage (2-3 minutes after dye injection) using a digital fundus camera (Heidelberg Retina Angiograph, Vista, CA).

\section{SD-OCT}

The preparation of mice was described in the section of laser-induced Mouse CNV model. The Bioptigen

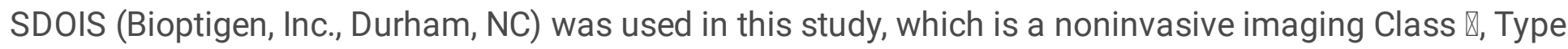
B, IPXO, continuous operation medical device. The SDOIS apparatus is comprised of a base system as well as an animal imaging mount and rodent alignment stage (AIM-RAS), which contains a SD-OCT hand held probe (HHP). After the HHP lens was situated close to the right eye of the animal, the InVivoVue Clinic application was activated and the scanning began- following setup of subject profile for image acquisition, we selected the rectangular scanning protocol consisting of a $3 \mathrm{~mm}$ by $3 \mathrm{~mm}$ perimeter with 1000 A-scans per B-scan with a total B-scan amount of 100. This a modification of the recommended parameters of $1.4 \mathrm{~mm}$ by $1.4 \mathrm{~mm}$ set by the company for performing rectangular scans.

\section{Western blot}

To obtain protein in choroids, mice were killed promptly by cervical vertebra dislocation, eyeballs were harvested instantly and put in cold PBS. Corneas, lenses, vitreouse and retina of mouse eyes were removed and the RPE-choroid tissues were put and chopped into homogenate using a tissue chopper (SONICS \&MATERIALS INC.; NEWTOWN, USA) in radio-immunoprecipitation assay (RIPA) lysis buffer with Phenylmethanesulfonyl fluoride (Beyotime biotechnology, China).

Proteins were separated by SDS-polyacrylamide gel electrophoresis, transferred to polyvinylidene difluoride membrane, and probed with antibodies specific for $\mathrm{Y}$-H2AX (1:1000 dilution, \#2577, CST), for Phospho-NF-kB p65 (Ser536) (1:1000 dilution, \#3033), for p65 (1:1000 dilution, \#8242, CST), for VEGFA (46154,Abcam), for p-STAT3 (9145S, CST), for GAPDH (1:5000, dilution, 60004-1-Ig, Proteintech) antibodies were used to determine protein amounts as a loading control. 


\section{Cell viability assay}

The Cell Titer 96 Aqueous One Solution cell proliferation assay (Promega, Madison, WI, USA) was performed. Briefly, RPE cells were seeded in 96-well flat-bottomed microliter plates in eight repeat cultures at a concentration of $1 \times 10^{4}$ cells/well. After treatment, each well was incubated with $20 \mu \mathrm{M}$ MTS assay solution for $2 \mathrm{~h}$ at $37^{\circ} \mathrm{C}$ and the absorbance was measured using an enzyme-linked immunosorbent assay plate reader at $490 \mathrm{~nm}$ emission wavelength. Cell viability was expressed as the percentage of absorbance in cells with indicated treatments to that in cells with solvent control treatment.

\section{Immunofluorescence}

Slides were either fixed with $\mathrm{MeOH}$ at $-20^{\circ} \mathrm{C}$ or with $4 \%$ formaldehyde at room temperature for 10 to 15 min, and were then incubated with blocking buffer (0.8× PBS, $50 \mathrm{mM} \mathrm{NaCl}, 0.5 \%$ Triton X100, $3 \%$ milk) for $1 \mathrm{~h}$, followed overnight by incubation at $4^{\circ} \mathrm{C}$ with primary antibody to $\mathrm{Y}-\mathrm{H} 2 \mathrm{AX}$ (ab2893,1/100, abcam) and mouse polyclonal antibody to TRF1 (ab10579, 1/100, abcam) in $0.8 \times$ PBS, $50 \mathrm{mM} \mathrm{NaCl}, 0.5 \%$ Triton $X 100$, and $3 \%$ milk. Cells were then washed three times for 10 min in $0.8 \times \mathrm{PBS}, 50 \mathrm{mM} \mathrm{NaCl}$, and $1.5 \%$ skimmed milk at RT. Incubation with donkey polyclonal anti-mouse ALEXA488 (A21202; Molecular Probes) and donkey polyclonal anti-rabbit ALEXA555 (A31752; Molecular Probes) antibodies was performed for $1 \mathrm{~h}$ at $37^{\circ} \mathrm{C}$ in the dark in $0.8 \times \mathrm{PBS}, 50 \mathrm{mM} \mathrm{NaCl}, 0.5 \%$ Triton X 100, and $3 \%$ skimmed milk. All antibody incubations were performed in a moist chamber. Cells were then washed three times for 10 min in $0.8 \times$ PBS, $50 \mathrm{mM} \mathrm{NaCl}$, and $0.5 \%$ Triton X 100. Slides were then rinsed in PBS, counterstained with DAPI, mounted in VECTASHIELD, and stored at $4^{\circ} \mathrm{C}$ in the dark.

\section{Chromosome PNA-FISH}

Briefly, cells were washed with PBS and $10 \mathrm{~mL}$ of fresh culture medium with $60 \mu \mathrm{L}$ of colcemid (10 $\mathrm{ng} / \mathrm{mL}$ ) added and incubated at $37^{\circ} \mathrm{C}$, after which the cells were collected. Cells were then centrifuged at $300 \times g$. The supernatant was then aspirated. Next, $25 \mathrm{~mL}$ of $\mathrm{KCl}$ were added and mixed by inverting. A total of $100 \mu \mathrm{L}$ of fresh fixative (methanol/acetic acid $=3 / 1$ ) was added and mixed. Incubated the tubes in a $37^{\circ} \mathrm{C}$ for $15 \mathrm{~min}$ and centrifuged at $300 \times \mathrm{g}$ at $4^{\circ} \mathrm{C}$. Then, added $30 \mathrm{~mL}$ of fresh fixative and incubated overnight. Centrifuged the fixed cells and aspirated the fixative, leaving $2 \mathrm{~mL}$ in the tube. Precooled slides were placed in the humidity chamber and the resuspended cells were added to a slide. We then allowed the slides to dry overnight.

Next, slides were fixed in $4 \%$ formaldehyde for $2 \mathrm{~min}$, followed by washing three times. Prewarmed $50 \mathrm{~mL}$ of $0.01 \mathrm{M} \mathrm{HCl}$ to $37^{\circ} \mathrm{C}$ and added $50 \mu \mathrm{L} / 10 \mathrm{~mL}$ of pepsin stock ( $100 \mu \mathrm{g} / \mu \mathrm{L}$, Sigma) to it. Slides were then put in the solution and incubated at $37^{\circ} \mathrm{C}$, after which the slides were fixed in $4 \%$ formaldehyde. Next, slides were dehydrated by 50,75 , and $100 \%$ ethanol. Once dry, applied $120 \mu \mathrm{L}$ of PNA probe in blocking buffer ( $70 \%$ deionized formamide, $100 \mathrm{mM}$ Tris, $\mathrm{pH} 7.2,1 \%$ blocking reagent). The slide was denatured at $80^{\circ} \mathrm{C}$ for $3 \mathrm{~min}$ and incubated for $2 \mathrm{~h}$ at $37^{\circ} \mathrm{C}$. Then, the slide washed twice in washing buffer I $(70 \%$ deionized formamide, $10 \mathrm{mM}$ Tris, $\mathrm{pH}$ 7.2) and three times in washing buffer II (0.05\% Tween-20, $50 \mathrm{mM}$ 
Tris, $\mathrm{pH} 7.4,150 \mathrm{mM} \mathrm{NaCl}$ ). Stained the slides in 4',6-diamidino-2-phenylindole (DAPI) and washed the slides in PBS. The slides were stored at $4^{\circ} \mathrm{C}$.

\section{Microscopy}

PNA-FISH assays were recorded on an AxioPlan microscope from ZEISS, equipped with a Plan-Apochrom at 63×, NA 1.4, oil immersion lens, and a cooled CCD camera (CoolSNAP HQ, Photometrics). Image acquisition, processing, and analysis software were from MetaMorph (Molecular Devices). Images of immunofluorescence were recorded using a confocal microscope from Leica.

\section{SA- $\beta$-gal staining}

The senescence-associated beta-galactosidase (SA- $\beta$-gal) staining assay was performed using an SA- $\beta$ gal staining kit (Beyotime, China) and performed as the manufacturer`s instructions.

\section{RNA analyses}

Total RNA samples were isolated using TRIzol (\#15596-018, Invitrogen) and then reverse transcribed into cDNAs using a kit from Takara (\#RR047A).

\section{RNA-seq and bioinformatics analyses}

RNA-seq was performed according to the manufacturer's guidelines and previous protocols (C-10365, Life Technologies) [28]. RNA deep-sequencing analyses were performed at BGI-Tech (Shanghai, China). For bioinformatics analyses, transcript structure and abundance were estimated using Cufflinks software and differential expression analysis was performed using Cuffdiff software. [29] The cutoff value of differential expression gene was: $\mid \log 2$ (fold change) $\mid>1$, p-value $<0.05$. Gene ontology (GO) enrichment analysis was performed using DAVID ver. 6.7 (Database for Annotation, Visualization and Integrated Discovery), which is a web-based application (https://david.ncifcrf.gov/)

\section{Real-time PCR (RT PCR) validation}

RT-PCR primer sequences were designed using Primer3 web software (version 4.0.0). The primer sequences used are provided in Additional file 2. The GAPDH gene was used to calculate the relative folddifferences based on comparative cycle threshold $\left(2^{-\Delta \Delta C t}\right)$ values. The RT-PCR procedure was as follows: $1 \mu \mathrm{L}$ of $\mathrm{cDNA}$ in $\mathrm{H}_{2} \mathrm{O}$ was added to $5 \mu \mathrm{L}$ of $2 \times$ SYBR Green buffer, $0.1 \mu \mathrm{M}$ each primer, and $\mathrm{H}_{2} \mathrm{O}$ to a final volume of $10 \mu \mathrm{L}$. Differences between the two samples were calculated using Student's $t$-test at a significance level of 0.05 in Graphpad Prism 6.0 software. All expression analysis was performed for three biological repeats and the average values of three repeats values were shown in the figures.

\section{Statistical analysis}

Based on the univariate test, continuous normal variables were expressed as the mean value \pm SD. Parametric variables of normal distribution were analyzed either by the two-tailed $t$-test or the $F$ test of 
ANVOA, followed by the Duncan test for each two group comparison. Results were considered significant at $p<0.05$. Statistical analysis was performed with Graphpad Prism 6.0 software.

\section{Results}

\section{Chrysin suppressed laser-induced CNV succesfully}

It has been demonstrated that intravitreally injected chrysin could significantly inhibit angiogenesis in laser-induced experimental CNV model [12]. However, the precise mechanism of this is unknown. Considering that intravitreally injection may cause other side effects [13], thus we wanted to know whether intragastrically administered chrysin would take positive effect in laser-induced CNV leision. Chrysin was administered intragastrically at $25 \mathrm{mg} / \mathrm{kg}$ daily for 3 days or one week after laser-treated, then we observed the CNV areas and CNV thickness via immunofluorescence staining of choroidal flatmount, SD-OCT and fluorescein angiograghy, respectively (Figs. 1A, C, E). The results showed that chrysin decreased both CNV area and thickness significantly (Figs. 1B, D). It indicated that administered intragastrically chrysin did help to inhibit angiogenesis in laser-induced CNV leision.

\section{Chrysin alleviated DNA damage of RPE cells in CNV lesion}

Since DNA damage is a common cause of retinal disease. It has been showed that the 8-OHdG level in aqueous humor was significantly higher in exudative AMD patients and correlated with macular lesion size [8], which indicated that oxidative DNA damage is associated with CNV. Therefore, we next explored whether chrysin suppressed CNV lesion via alleviating DNA damage. After 7 days intragastrically administered with chrysin at $25 \mathrm{mg} / \mathrm{kg}$ daily in laser-induced CNV mice, we compared the expression of $\mathrm{Y}^{-}$ $\mathrm{H} 2 \mathrm{AX}$ protein by immunofluorescence in CNV lesion, which is a sensitive indicator of double-strand DNA breaks. Interestingly, we found that the expression of $\mathrm{Y}-\mathrm{H} 2 \mathrm{AX}$ was mainly in RPE cells rather than vascular endothelial cells, and chrysin could significantly decrease the number of $\mathrm{Y}-\mathrm{H} 2 \mathrm{AX}$ foci per cell and the percentage of $Y-H 2 A X$ positive cell (Figs. 2A-B, Additional file 1). Subsequently, we investigated the level of $\mathrm{Y}-\mathrm{H} 2 \mathrm{AX}$ expression in retina and choroidal-RPE complex respectively. It showed that the expression of $\mathrm{Y}-\mathrm{H} 2 \mathrm{AX}$ was mainly originated from choroidal-RPE complex and chrysin could reduce the $\mathrm{Y}-\mathrm{H} 2 \mathrm{AX}$ expression, which was consistent with the expression of VEGFA expression. These results indicated that chrysin could compromise DNA damage in CNV lesion and stress-induced DNA damage of RPE cells played an important role in this pathogenesis.

\section{Chrysin rescued stress-induced DNA damage, especially telomere deletion, to suppress inflammation in RPE cells in vitro}

To further confirm the effect of chrysin on stress-induced DNA damage in RPE cells, we used the in vitro model of RPE cells with photosensitization of A2E, which has been showed to extremely reflect stressinduced DNA damage level and could mimic the early pathogenesis of AMD [9]. To determine the effect of chrysin on the viability of RPE cells, cells were incubated with $3 \mu \mathrm{mol} / \mathrm{L}$ chrysin for 24 hours firstly and then cell viability was examined by MTT assay. It showed that the viability of RPE cells increased with 
chrysin incubation under photosensitization of $\mathrm{A} 2 \mathrm{E}$, and the result was consistent with the treatment of NAC, which has demonstrated to reduce DNA damage effectively(Fig. 3A).

Further, we explored whether chrysin could compromise the stress-induced DNA damage based on the level of $Y-H 2 A X$ expression by western blotting. We observed a decrease in the level of $Y-H 2 A X$ in RPE cells with $3 \mu \mathrm{mol} / \mathrm{L}$ chrysin incubation under photosensitization of $A 2 E$, which is consistent with the effect of NAC (Fig. 3B). Since telomeres, located at the end of chromosome, are special repeat DNA fragments, which are particularly sensitive to stress. We have demonstrated photosensitization of $A 2 E$ induced telomere loss (both single and double strand) in the previous study. Thus, we explored whether chrysin could have protective effect on telomere deletion. We evaluated the telomere deprotection by monitoring co-localization of the shelterin TRF1 (used as a telomere marker) with $\mathrm{y}-\mathrm{H} 2 \mathrm{AX}$ (named TIF for telomere dysfunction-induced foci). It showed that chrysin alleviated the number of $\mathrm{Y}-\mathrm{H} 2 \mathrm{AX}$ foci per nucleus. Importantly, chrysin decreased the number of TIF per nucleus (Figs. 3C-E). Then, we examined telomeres for abnormalities using the telomeric peptide nucleic acid (PNA) probe in metaphase spread staining. Interestingly, chrysin significantly rescued telomere erosion caused by photosensitization of A2E (Figs. 4A-B).

Since chrysin successfully decreased DNA damage (especially telomere damage), which is associated with cell senescence. Meanwhile, it has been demonstrated that photosensitization of A2E could accelerate RPE senescence in our previous study [9]. Then, we determined whether chrysin could compromise RPE senescence under photosensitization of A2E. So, we monitored SA- $\beta$-galactosidase staining as a marker for cellular senescence. Our results showed that chysin significantly decreased the percentage of SA- $\beta$-galactosidase positive cell (Figs. 4C-D). Considering that cellular senescence usually coupled with the secretion of various pro-inflammatory molecules (known as the senescence associated secretory phenotype (SASP)), we evaluated the expression of pro-inflammatory cytokines by RT-PCR. As expected, we found that chrysin decreased the expression of IL6 and VEGF (Figs. 4E-F). We conclude that chrysin compromise stress-induced DNA damage, especially telomere erosion, simultaneously alleviate secretion of pro-inflammatory cytokines. Also, this may indicated that chrysin may play a role in reduction of inflammatory response.

\section{Chrysin suppressed stress-induced inflammation, especially IL17 pathway through inactivation of STAT3, thus inhibited laser-induced angiogenesis in vivo}

To investigate the mechanisms involved in the anti-angiogenesis effect of chrysin, we explored how chrysin influences gene expression in CNV lesion using RNA-Seq and bioinformatics analyses. We identified 897 genes that were differentially expressed with chrysin treatment, including 149 genes up regulated and 748 genes down regulated. To understand the involved pathway of the differentially expressed genes (DEGs), we performed KEGG pathway annotation. We found that the "IL-17 signaling pathway" and "cytokine-cytokine receptor interaction" pathway were significantly enriched (Fig. 5A).

Interestingly, it has been found the significantly increase of IL-17 in the sera of AMD patients, suggesting that IL-17 may contributes to CNV and AMD[14]. Hence, we focused on the genes enriched to the IL-17 
signaling pathway, which was shown in Fig. 5B. Further, we selected 9 genes for validation by RT-qPCR. The results were agreement with those found in the RNA-Seq analysis (Fig. 6A). The transcript level of CCL 17 was markedly increased in CNV lesion and decreased with chrysin treated, which indicated that CCL 17 may play role in CNV pathogenesis. To our knowledge, this was the first study that reported the possible relationship of $C C L 17$ and $C N V$, but the underlining mechanism need to be further investigated. As expected, the expression of IL17A, IL1 $\beta$ and VEGF was increased significantly and the increasement was suppressed after chrysin treatment, which is consistent with the precious study.

To increase our understanding of the mechanism evolved in suppressing inflammation effect of chrysin, we further explored the transcription regulators. It has been demonstrated that DNA damage response induces inflammation by inhibiting GATA4 via activating transcription factor NFKB [15]. Thus, we explored the expression of phospho-p65 (Ser536) and total p65. Surprisingly, the expression of p65 changed slightly both in CNV and chrysin treated group (Fig. 5C). Otherwise, the expression of phosphop65 was significantly increased in CNV lesion, but changed lightly after chrysin treatment. These results suggested that chrysin may effect slightly on NFKB translocation in laser-induced CNV lesion. Notably, CNV generation was accompanied by STAT3 activation [16] and one previous study had indicated the crosstalk between STAT3 and IL17 pathway [17]. We further tested the expression level of p-STAT3, and it showed a remarkably decrease after chrysin treatment (Fig. 5C). These results suggest that chrysin downregulated IL17 pathway mainly through inactivation of STAT3.

\section{Discussion}

In this study, we found that chrysin suppressed angiogenesis by alleviating DNA damage mainly in RPE cells, further decreasing the secretory of proinflammatory cytokines and improving the disturbed immunohomeostasis in retina. Our results indicate that RPE cell dysfunction plays an important role in the pathogenesis of CNV. In addition, chrysin decreased DNA damage, especially telomere erosion, resulting in the percentage of senescence cell reduced and alleviating the parainflammation in a stress-induced RPE damage model in vitro. Also, our results suggest that chrysin mainly down regulate the IL17 pathway in this inflammatory imbalance environment. Totally, our results emphasize the critical role of interplay between DNA damage, RPE cell dysfunction, inflammatory imbalance and angiogenesis in CNV development. Besides, chrysin may be of promising therapeutic value for the treatment of neovasvular diseases.

Over the past several years, observation shows that activation of other pathogenic pathways have compromise the beneficial of anti-VEGF agents, resulting in poor response or no response[1]. Indeed, apart from VEGF, multiple factors involve in pathological angiogenesis, including a combination of parainflammation as well as heightened inflammasome activation and chronic inflammatory responses [18, 19]. RPE cells are critically important in maintaining retinal immuno-homeostasis, which located as a monolayer of polarized cell, sustaining the outer blood-retinal barrier while it regulates nutrient and oxygen delivery to the outer retina and removal of metabolic waste from the photoreceptors [20]. Our previous study has shown that dysfunctional RPE cells create para-inflammation environment [9]. In 
previous study, we found that acute injury of RPE cells increase the secretory of pro-inflammatory cytocins through activation of STAT3 and NFKB. These suggest that besides vascular endothelial cells, the role of RPE dysfunction in pathological angiogenesis must be taken into account. Thus, to better understanding the mechanism underling the interplay of RPE dysfunction and inflammation response may further help to identify new and better antiangiogenic regents.

In this work, we found that DNA damage is a notable inducer of RPE alterations in cellular phenotypes. In our study, we demonstrated that the expression of $\mathrm{YH} 2 \mathrm{AX}$ was significantly increased both by westernblot and immunofluorescence mainly in RPE cells in CNV lesion. Also, chrysin successfully decreased the level of DNA damage. Particularly, we found chrysin could especially protect telomere from deletion in stress-induced RPE cells. To our limited knowledge, this is the first report that identified the antiangiogenesis effect of chrysin in laser-induced CNV model through alleviating DNA damage in RPE cells. Importantly, we first prove the protective effect of chrysin on telomere. In the previous study, chrysin was identified to be able to drastically deprotect telomeres against DNA damage response in a highthroughput screening assay for drugs altering telomeres, which is inconsistent with our results [21]. In detail, we found the concentration of chrysin was extremely different, which in our research the dose of chrysin was much lower. This indicates that the effect of chrysin on telomeres may be dose-dependent, which need to be further evaluated.

Apart from the effect of DNA damage on RPE cell phenotype, it has been found that DNA damage of RPE cells was the primary cause of disturbed immuno-homestasis. This finding is substantiated by several lines of evidence. One recent study indicated that DNA damage is associated with inflammation and parainflammation, which is an adaptive response of the immune system to low levels of tissue stress [22]. It has been showed that DNA damage induced a secretory program in quiescent TME, including proinflammation cytokines IL-1 $\beta$, IL-6 and IL-8, which fostered adverse cancer phenotypes [23]. Additionally, DNA damage response induced inflammation and senescence by inhibiting GATA4, resulting in NFKB activation and SASP induction [15]. In our study, results of RNA-Seq revealed that acute damage of RPE induced secretion of numerous proinflammation cytokines in CNV lesion and chrysin dramatically down-regulated these cytokines by inactivation of STAT3. In vitro, chrysin compromised cellular senescence, simultaneously, decreased pro-inflammatory cytokines in stress-induced DNA damage of RPE cells. These results underlined the protective effect on immuno-homeostasis of chrysin.

Especially, KEGG pathway analysis showed that chrysin mainly suppresses the IL17 pathway in laserinduced CNV. And we confirmed chrysin could significantly decrease the expression of CCL17, IL 17A and other related genes. The previous study showed that IL17 is significantly increased in human eyes with AMD[14], and blocking IL17 in eyes of mice was found to be neuroprotective [24]. Recent publications have indicated that the IL17 present in the eye during age-dependent degeneration as well as in mouse

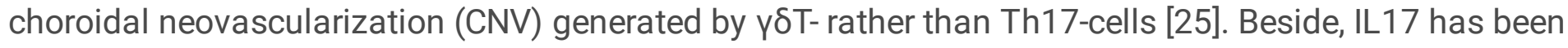
shown to increase VEGF production and VEGF can promote IL17 producing үठT-cell accumulation [25]. In the tumor microenvironment, Chung et al has shown that IL-17A is responsible for mediating resistance to the antiangiogenic effects of VEGF blockade [26]. Totally, these evidences indicate that IL-17 pathway 
may play critical role in the disturbed immuno-homeostasis environment and pathological angiogenesis in laser-induced CNV.

\section{Conclusions}

In conclusion, we reveals that the DNA damage of RPE cells is responsible for pathological angiogenesis, causing disturbed immuno-homeostasis and pro-angiogenic environment, indicating the important crosstalk between DNA damage, RPE dysfunction, inflammatory imbalance and angiogenesis play a critical role in pathology of laser-induced CNV. Our results also suggest that chrysin may be a promising therapeutic supplement for the treatment of CNV.

\section{Abbreviations}

CNV: Choroidal neovascularization; WAMD: wet age-related macular degeneration; RPE: retinal pigment epithelium; SASP: senescence-associated secretory phenotype; STAT: signal transducer and activator of transcription; PNA: peptide nucleic acid; DEGs: differentially expressed genes; GATA4: GATA binding protein 4

\section{Declarations}

\section{Acknowledgements}

Thanks to Wenqi Li and Hongjie Shen from Epigenetics Key Laboratory of Institutes of Biomedical Sciences (IBS) of Fudan University for their help with RNA-Seq analysis.

\section{Authors' Contributions}

Jing Wang and Qiyu Bo conducted the experiments; Minwen Zhou and Hong Wang conducted the statistical analysis; Yuwei Wang, Min Li and Hong Zhu conducted the word processing and graphics; Fenghua Wang, Mei Jiang and Xiaodong Sun designed the experiments; Jing Wang and Xiaodong Sun wrote the paper

\section{Funding}

This study was supported by the National Natural Science Foundation of China (grant numbers 81900869, 81730026), the National Key R\&D Program (grant numbers 2019YFC0840607, 2017YFA0105301), Science and Technology Commission of Shanghai Municipality (grant numbers 17411953000, 19495800700) and Shanghai Sailing Program (grant numbers 19YF1439500)

Funding institutions had no role in the study design, data collection and analysis, the decision to publish, or preparation of the manuscript.

\section{Availability of data and materials}


The datasets used during the current study are available from the corresponding author on reasonable request.

\section{Ethics approval and consent to participate}

All animal experiments were approved by the Institutional Animal Care and Use Committee of Shanghai Jiao Tong University (Shanghai, China). The study followed by the guidelines of the ARVO statement for the Use of Animals in Ophthalmic and Vision Research.

\section{Consent for publication}

Not applicable.

\section{Competing interests}

The authors declare no competing interests.

\section{Author details}

${ }^{1}$ Department of Ophthalmology, Shanghai General Hospital, Shanghai Jiao Tong University School of Medicine, No. 100 HaiNing Road Shanghai 200080 (PR China)

${ }^{2}$ Shanghai Key Laboratory of Ocular Fundus Diseases, Shanghai, China

${ }^{3}$ Shanghai Engineering Center For Visual Science And Photomedicine, Shanghai, China

${ }^{4}$ National Clinical Research Center for Eye Diseases, Shanghai, China

\section{References}

1. Yang $\mathrm{S}$, Zhao J, Sun X: Resistance to anti-VEGF therapy in neovascular age-related macular degeneration: a comprehensive review. Drug Des Devel Ther 2016, 10:1857-1867.

2. Arcinue CA, Ma F, Barteselli G, Sharpsten L, Gomez ML, Freeman WR: One-year outcomes of aflibercept in recurrent or persistent neovascular age-related macular degeneration. Am J Ophthalmol 2015, 159:426-436.

3. Forrester JV, Xu H: Good news-bad news: the Yin and Yang of immune privilege in the eye. Front Immunol 2012, 3:338.

4. Liu J, Copland DA, Horie S, Wu WK, Chen M, Xu Y, Paul MB, Mack M, Xu H, Nicholson LB, Dick AD: Myeloid cells expressing VEGF and arginase-1 following uptake of damaged retinal pigment epithelium suggests potential mechanism that drives the onset of choroidal angiogenesis in mice. Plos One 2013, 8:e72935.

5. Liu J, Copland DA, Theodoropoulou S, Chiu HA, Barba MD, Mak KW, Mack M, Nicholson LB, Dick AD: Impairing autophagy in retinal pigment epithelium leads to inflammasome activation and enhanced 
macrophage-mediated angiogenesis. Sci Rep 2016, 6:20639.

6. Luo X, Puig O, Hyun J, Bohmann D, Jasper H: Foxo and Fos regulate the decision between cell death and survival in response to UV irradiation. Embo J 2007, 26:380-390.

7. Santocono M, Zurria M, Berrettini M, Fedeli D, Falcioni G: Influence of astaxanthin, zeaxanthin and lutein on DNA damage and repair in UVA-irradiated cells. J Photochem Photobiol B 2006, 85:205-215.

8. Lau LI, Liu CJ, Wei YH: Increase of 8-hydroxy-2'-deoxyguanosine in aqueous humor of patients with exudative age-related macular degeneration. Invest Ophthalmol Vis Sci 2010, 51:5486-5490.

9. Wang J, Feng Y, Han P, Wang F, Luo X, Liang J, Sun X, Ye J, Lu Y, Sun X: Photosensitization of A2E triggers telomere dysfunction and accelerates retinal pigment epithelium senescence. Cell Death Dis 2018, 9:178.

10. Lv PC, Cai TT, Qian Y, Sun J, Zhu HL: Synthesis, biological evaluation of chrysin derivatives as potential immunosuppressive agents. Eur J Med Chem 2011, 46:393-398.

11. Middleton EJ, Kandaswami C, Theoharides TC: The effects of plant flavonoids on mammalian cells: implications for inflammation, heart disease, and cancer. Pharmacol Rev 2000, 52:673-751.

12. Song JH, Kim YH, Lee SC, Kim MH, Lee JH: Inhibitory Effect of Chrysin (5,7-Dihydroxyflavone) on Experimental Choroidal Neovascularization in Rats. Ophthalmic Res 2016, 56:49-55.

13. Brown DM, Michels M, Kaiser PK, Heier JS, Sy JP, lanchulev T: Ranibizumab versus verteporfin photodynamic therapy for neovascular age-related macular degeneration: Two-year results of the ANCHOR study. Ophthalmology 2009, 116:57-65.

14. Liu B, Wei L, Meyerle C, Tuo J, Sen HN, Li Z, Chakrabarty S, Agron E, Chan CC, Klein ML, et al: Complement component C5a promotes expression of IL-22 and IL-17 from human T cells and its implication in age-related macular degeneration. $J$ Trans/ Med 2011, 9:1-12.

15. Kang C, Xu Q, Martin TD, Li MZ, Demaria M, Aron L, Lu T, Yankner BA, Campisi J, Elledge SJ: The DNA damage response induces inflammation and senescence by inhibiting autophagy of GATA4. Science 2015, 349:a5612.

16. Izumi-Nagai K, Nagai N, Ozawa Y, Mihara M, Ohsugi Y, Kurihara T, Koto T, Satofuka S, Inoue M, Tsubota $\mathrm{K}$, et al: Interleukin- 6 receptor-mediated activation of signal transducer and activator of transcription-3 (STAT3) promotes choroidal neovascularization. Am J Pathol 2007, 170:2149-2158.

17. Zanin-Zhorov A, Weiss JM, Nyuydzefe MS, Chen W, Scher JU, Mo R, Depoil D, Rao N, Liu B, Wei J, et al: Selective oral ROCK2 inhibitor down-regulates IL-21 and IL-17 secretion in human T cells via STAT3-dependent mechanism. Proc Natl Acad Sci U S A 2014, 111:16814-16819.

18. Nussenblatt RB, Lee RW, Chew E, Wei L, Liu B, Sen HN, Dick AD, Ferris FL: Immune responses in agerelated macular degeneration and a possible long-term therapeutic strategy for prevention. Am J Ophthalmol 2014, 158:5-11.

19. Xu H, Chen M, Forrester JV: Para-inflammation in the aging retina. Prog Retin Eye Res 2009, 28:348368. 
20. Rowe-Rendleman C, Glickman RD: Possible therapy for age-related macular degeneration using human telomerase. Brain Res Bull 2004, 62:549-553.

21. Boussouar A, Barette C, Nadon R, Saint-Leger A, Broucqsault N, Ottaviani A, Firozhoussen A, Lu Y, Lafanechere L, Gilson E, et al: Acacetin and chrysin, two polyphenolic compounds, alleviate telomeric position effect in human cells. Mol Ther Nucleic Acids 2013, 2:e116.

22. Chen $\mathrm{M}, \mathrm{Xu} \mathrm{H}$ : Parainflammation, chronic inflammation, and age-related macular degeneration. $J$ Leukoc Biol 2015, 98:713-725.

23. Gomez-Sarosi L, Sun Y, Coleman I, Bianchi-Frias D, Nelson PS: DNA Damage Induces a Secretory Program in the Quiescent TME that Fosters Adverse Cancer Phenotypes. Mol Cancer Res 2017, 15:842-851.

24. Talia DM, Deliyanti D, Agrotis A, Wilkinson-Berka JL: Inhibition of the Nuclear Receptor RORgamma and Interleukin-17A Suppresses Neovascular Retinopathy: Involvement of Immunocompetent Microglia. Arterioscler Thromb Vasc Biol 2016, 36:1186-1196.

25. Hasegawa E, Sonoda KH, Shichita T, Morita R, Sekiya T, Kimura A, Oshima Y, Takeda A, Yoshimura T, Yoshida S, et al: IL-23-independent induction of IL-17 from gammadeltaT cells and innate lymphoid cells promotes experimental intraocular neovascularization. $J$ Immunol 2013, 190:1778-1787.

26. Chung AS, Wu X, Zhuang G, Ngu H, Kasman I, Zhang J, Vernes JM, Jiang Z, Meng YG, Peale FV, et al: An interleukin-17-mediated paracrine network promotes tumor resistance to anti-angiogenic therapy. Nat Med 2013, 19:1114-1123.

27. Feng J, Chen X, Sun X, Wang F, Sun X: Expression of endoplasmic reticulum stress markers GRP78 and $\mathrm{CHOP}$ induced by oxidative stress in blue light-mediated damage of A2E-containing retinal pigment epithelium cells. Ophthalmic Res 2014, 52:224-233.

28. Guo R, Zheng L, Park JW, Lv R, Chen H, Jiao F, Xu W, Mu S, Wen H, Qiu J, et al: BS69/ZMYND11 reads and connects histone H3.3 lysine 36 trimethylation-decorated chromatin to regulated pre-mRNA processing. Mol Cell 2014, 56:298-310.

29. Trapnell C, Roberts A, Goff L, Pertea G, Kim D, Kelley DR, Pimentel H, Salzberg SL, Rinn JL, Pachter L: Differential gene and transcript expression analysis of RNA-seq experiments with TopHat and Cufflinks. Nat Protoc 2012, 7:562-578.

\section{Figures}


A

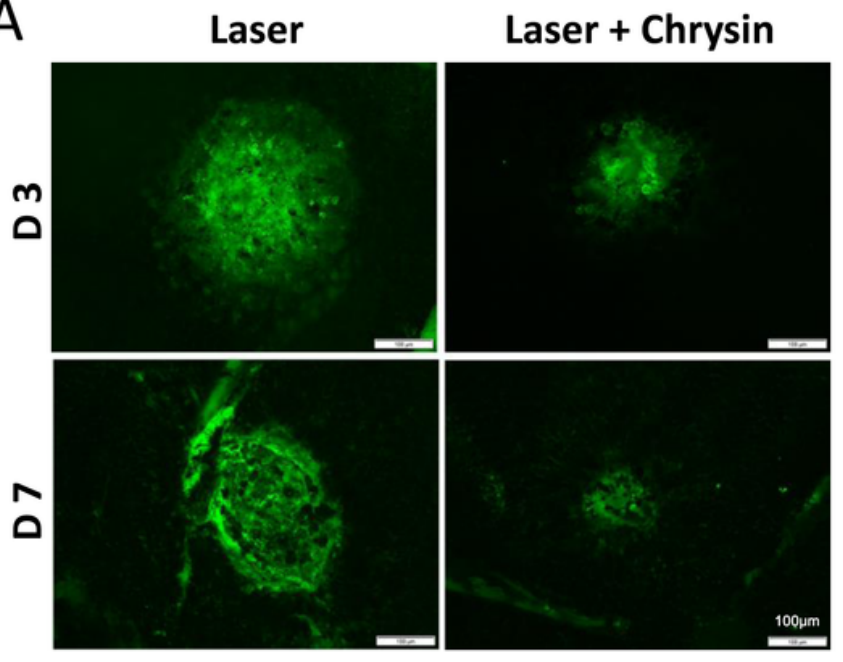

C

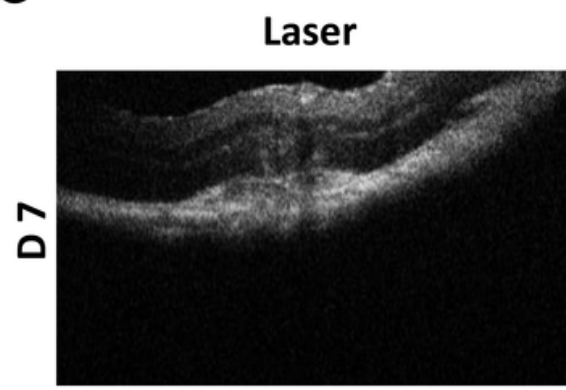

$E$

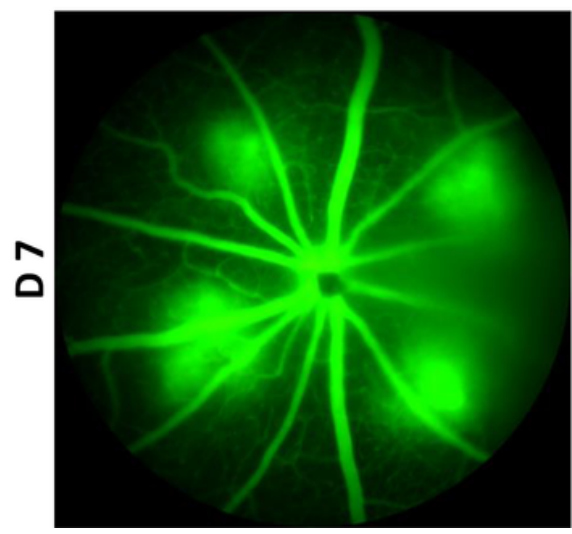

Laser+Chrysin

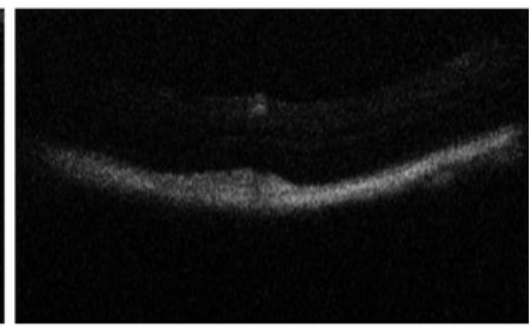

Laser+Chrysin
B

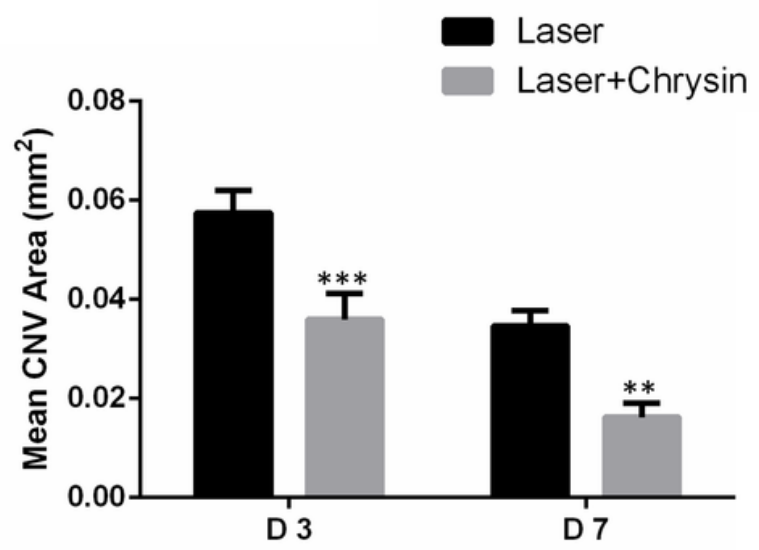

D

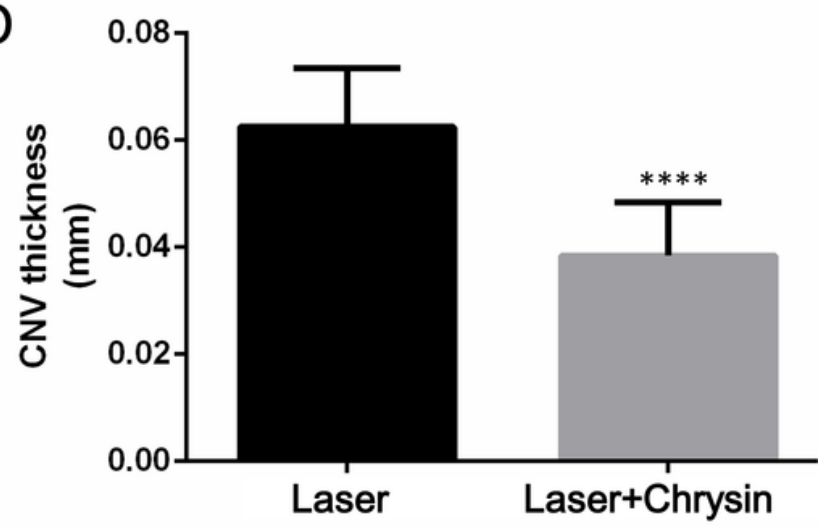

Figure 1

Chrysin suppressed laser-induced CNV in vivo A. Representative images of choroidal flatmounts stained with FITC-labeled isolectin-B4. The experiment was performed at least three repeats independently. B. Statistical analysis of CNV area shown in A. The data are presented as means \pm SD. $* \star$ indicates $p$ value < $0.01, * \star \star$ indicates $p$ value $<0.001$ compared to the laser-treated group. C. Representative images of SDOCT. The experiment was performed at least three repeats independently. D. Statistical analysis of CNV thickness shown in C. The data are presented as means \pm SD. $* \star \star \star$ indicates $p$ value $<0.0001$ compared to the laser-treated group. E. Representative microscopic images of fluorescence angiography. The experiment was performed at least three repeats independently. 


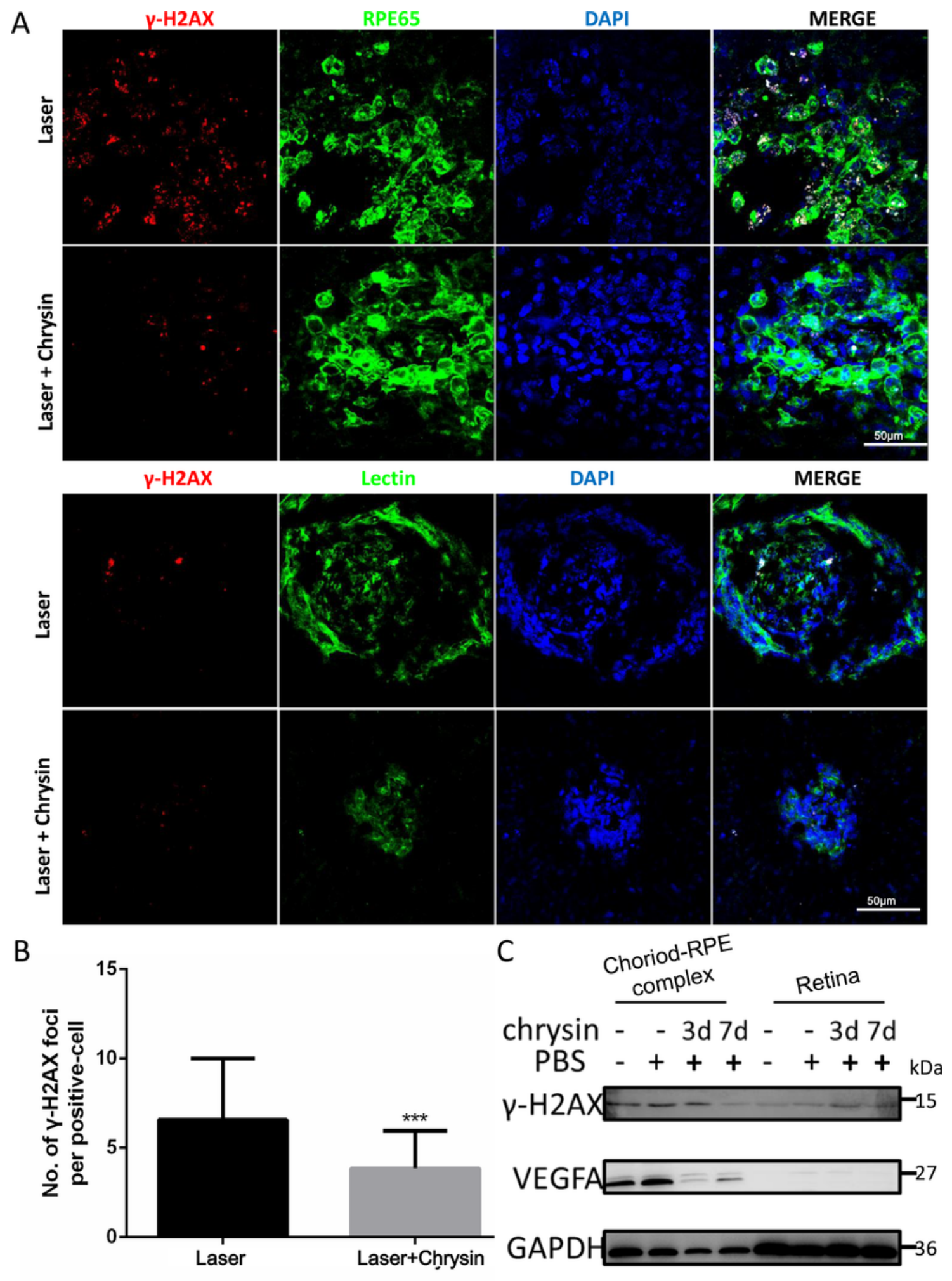

Figure 2

Chrysin alleviated DNA damage of RPE cells in CNV lesion A. Representative images of confocal sections of immunofluorescence assay in retina- choroidal complex after laser treated. Meanwhile, the chrysintreated group has been administered chrysin intragastrically at $25 \mathrm{mg} / \mathrm{kg}$ daily for 1 week. $\mathrm{Y}-\mathrm{H} 2 \mathrm{AX}$ foci are labeled red. B. Quantification of the number of $\mathrm{Y}-\mathrm{H} 2 \mathrm{AX}$ foci per nucleus in positive RPE cells. The experiment was performed independently at least three repeats. The data are presented as means \pm SD. 
$\star \star \star *$ indicates $p$ value $<0.001$ compared to the laser-treated group. C. Western blot showing $\mathrm{Y}-\mathrm{H} 2 \mathrm{AX}$ and VEGF proteins in choroid and retina respectively after laser treated with or without chrysin.

A

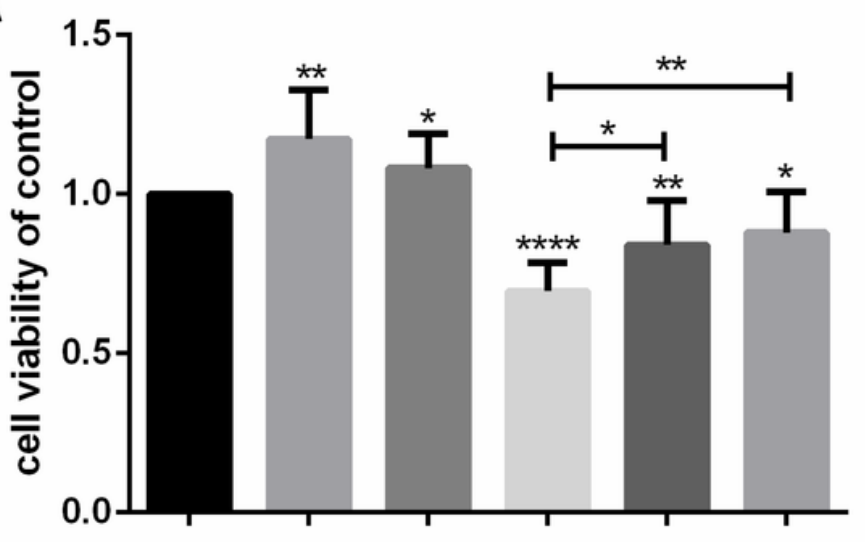

$\mathrm{A} 2 \mathrm{E}(25 \mu \mathrm{M}) \quad 0 \quad 0 \quad 0++$

Blue light - $\quad-\quad-\quad+\quad+\quad+$

$\mathrm{NAC}(\mathrm{mM}) 0 \quad 1 \quad 001000$

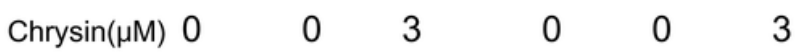

C

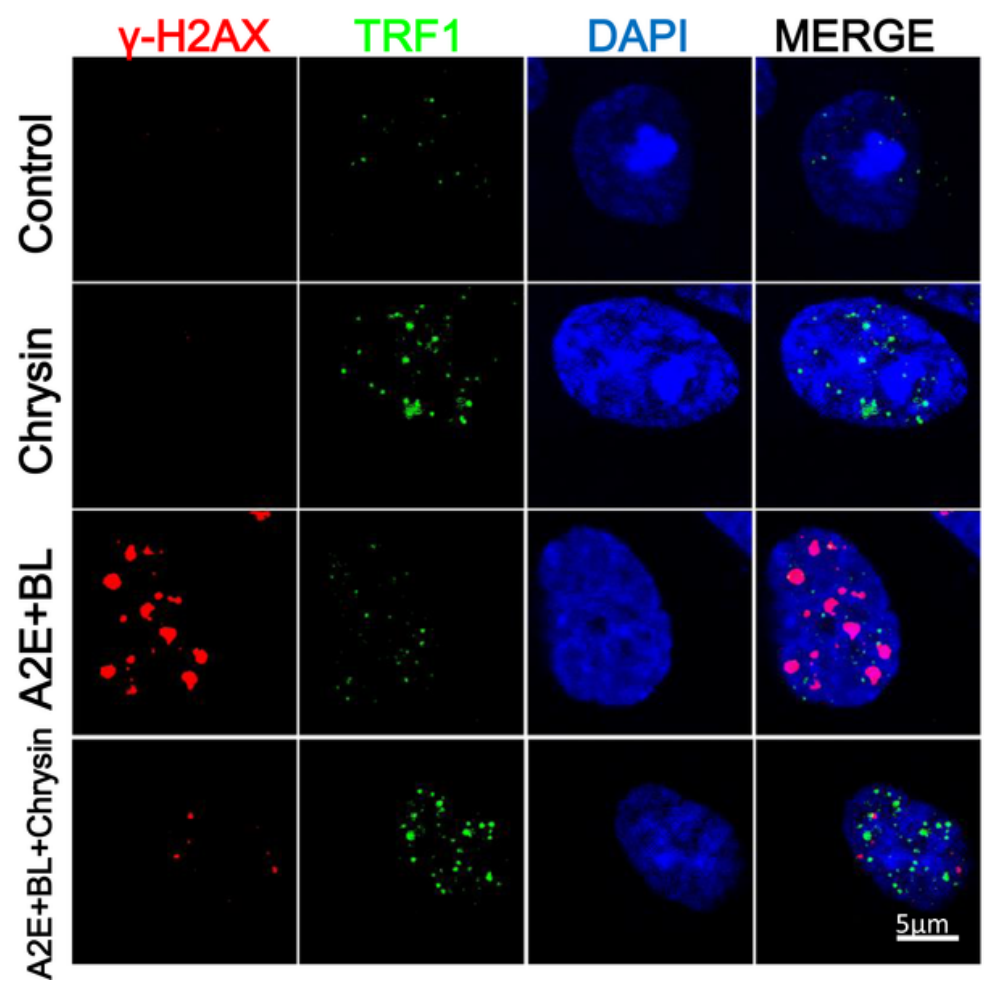

B

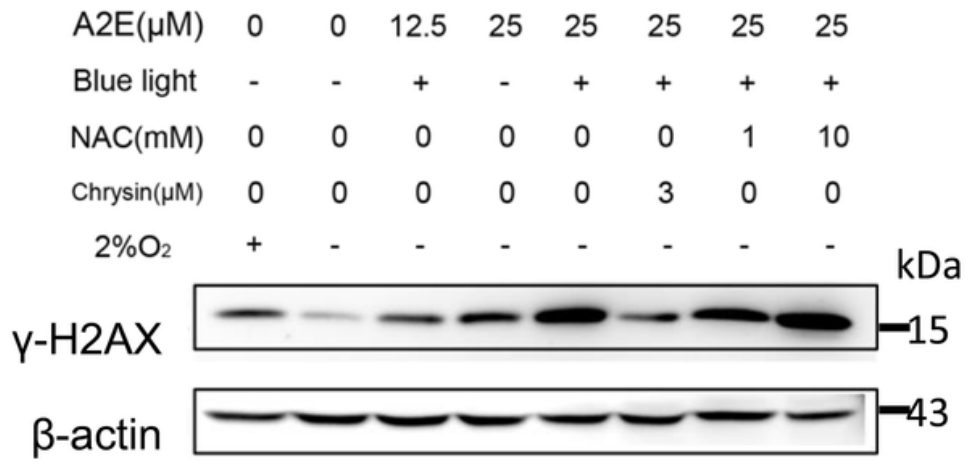

D

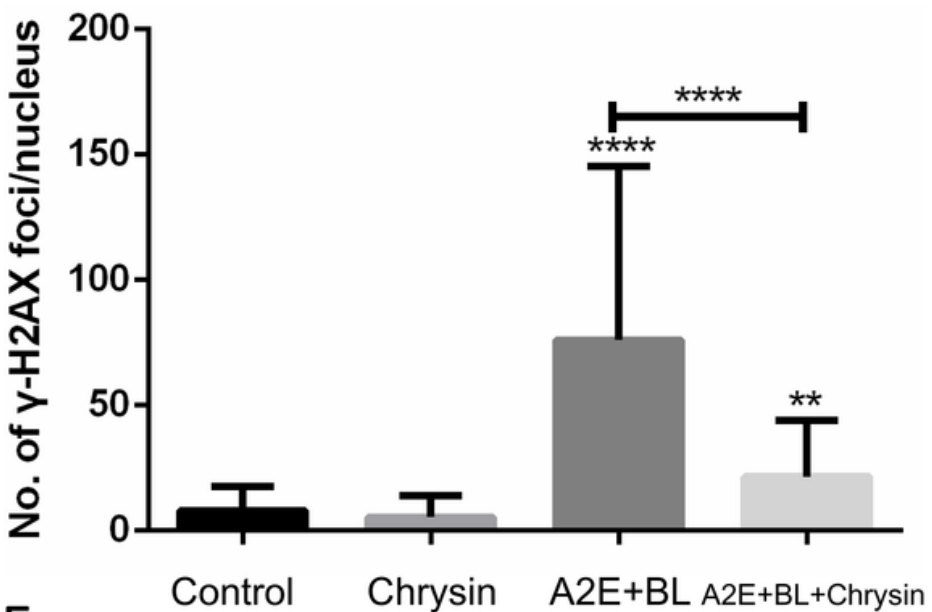

$\mathrm{E}$

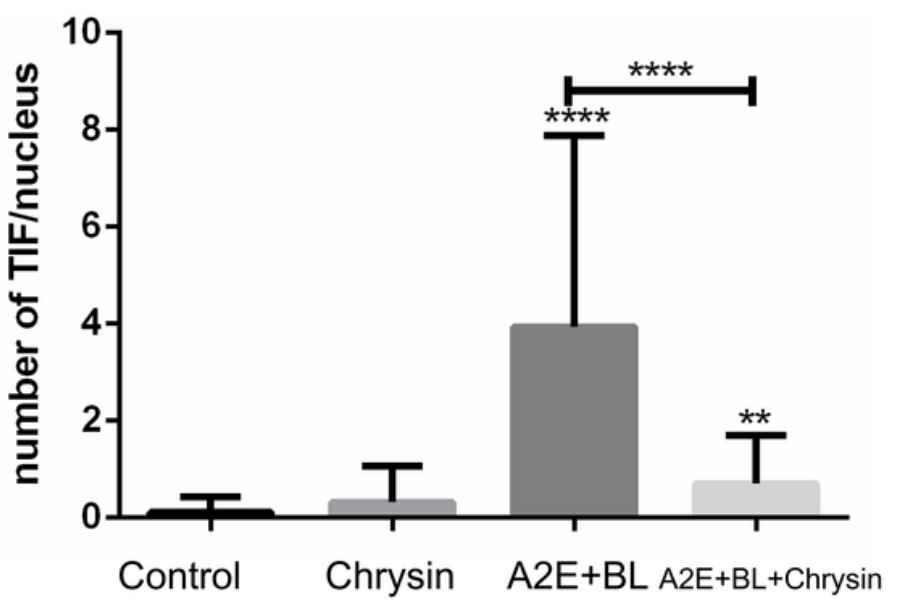

Figure 3

Chrysin rescued stress-induced DNA damage in RPE cells. A. MTT assay was performed in RPE cells under photosensitization of $A 2 E$ with or without chrysin. Data are presented as the means $\pm S D$. * indicates $p$ value $<0.05$, $\star \star$ indicates $p$ value $<0.01$, $\star \star \star \star$ indicates $p$ value $<0.0001$ compared to the control. The experiment was performed at least three repeats independently. B. Western blot showing $\mathrm{Y}^{-}$ 
H2AX proteins in RPE cells under photosensitization of A2E with or without chrysin treatment. C. Representative images of confocal sections of immunofluorescence assay in RPE cells under photosensitization of A2E with or without chrysin. $\mathrm{Y}-\mathrm{H} 2 \mathrm{AX}$ foci are labeled red and TRF1 are labeled green. D. Quantification of the number of $\mathrm{Y}-\mathrm{H} 2 \mathrm{AX}$ foci per nucleus in RPE cells treated with $3 \mu \mathrm{M}$ chrysin or $25 \mu \mathrm{M}$ A2E under photosensitization. Data are presented as means $\pm S D$. ** indicates $p$ value $<0.01$, $\star \star \star \star$ indicates $p<0.0001$ compared to the control. E. Quantification of TIFs per nucleus in RPE cells with $3 \mu \mathrm{M}$ chrysin or $25 \mu \mathrm{M}$ A2E under photosensitization. The data are presented as means \pm SD. ** indicates $p$ value $<0.01, * \star \star \star$ indicates $p<0.0001$ compared to the control. 
A

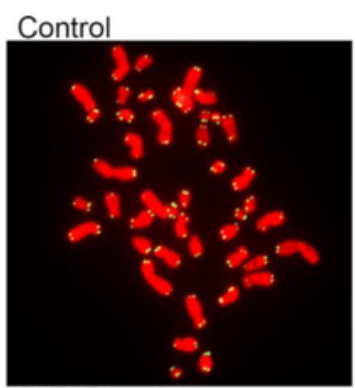

A2E+Blue light

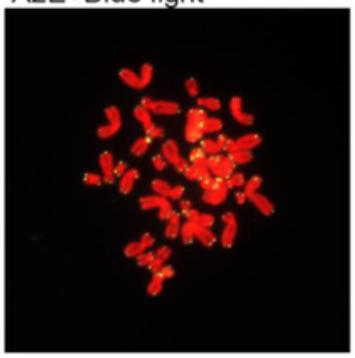

C

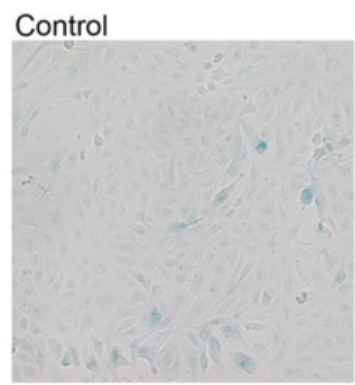

$\mathrm{A} 2 \mathrm{E}+$ Blue light A2E+Blue light+Chrysin

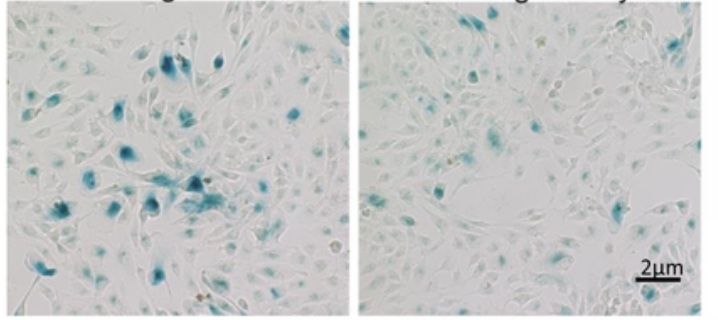

$\mathrm{E}$
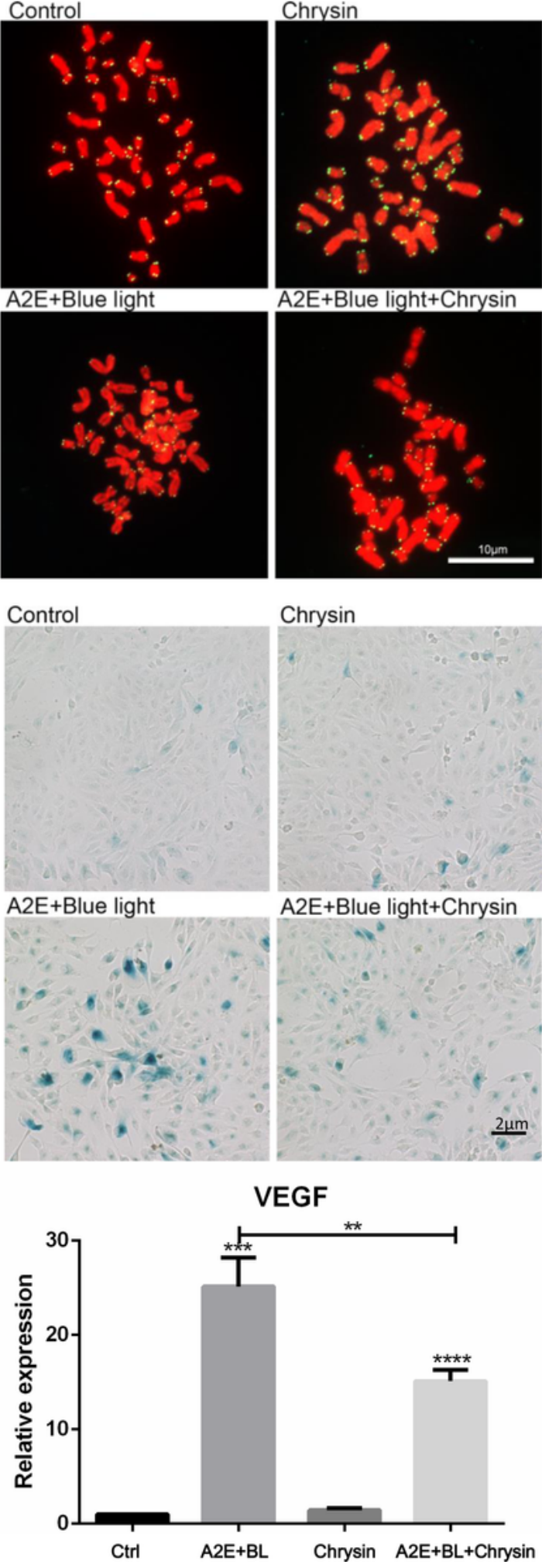

A2E+Blue light+Chrysin

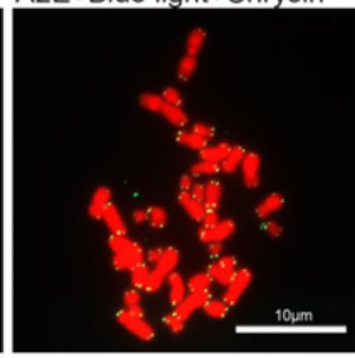

Chrysin

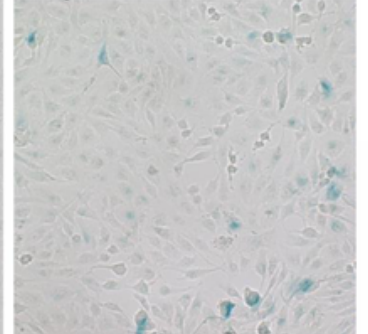

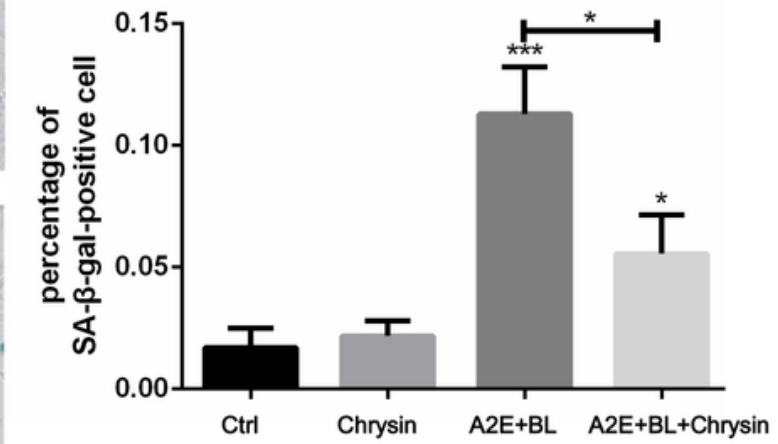

$\mathrm{F}$

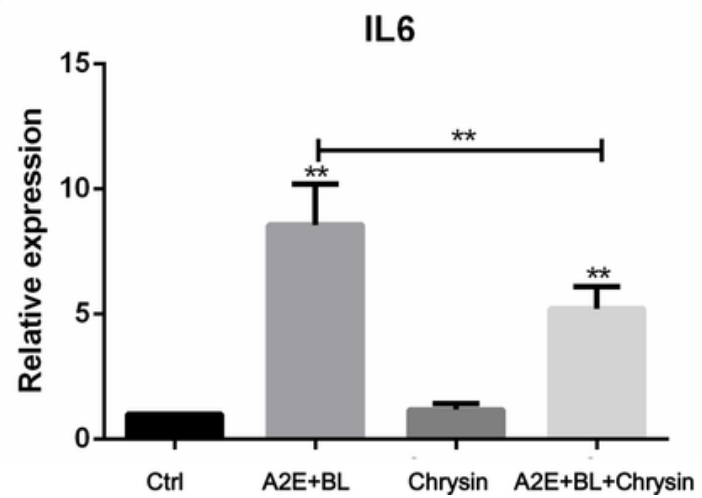

Figure 4

Chrysin could alleviate telomere deletions, thus rescue cellular senescence and stress-induced inflammation A. Representative images of telomere FISH in metaphase spreads of RPE cells treated with $3 \mu \mathrm{M}$ chrysin or $25 \mu \mathrm{M}$ A2E under photosensitization. Telo-foci were stained with a PNA probe and DNA was stained with DAPI. B. Quantitative analysis of telomere deletions of RPE cells treated with $3 \mu \mathrm{M}$ chrysin or $25 \mu \mathrm{M}$ A2E under photosensitization. Data are presented as means \pm SD. * indicates $p$ value 
$<0.05, * \star \star$ indicates $p$ value $<0.001, \star \star \star \star$ indicates $p<0.0001$ compared to the control compared to the control. C. Representative microscopic images of $\beta$-galactosidase staining in RPE cells treated with $3 \mu \mathrm{M}$ chrysin or $25 \mu \mathrm{M} \mathrm{A2E}$ under photosensitization. $P D L=25$. D. Quantification of the percentage of cells with positive SA- $\beta$-gal staining shown in $C$. * indicates $p$ value $<0.05$, $* \star *$ indicates $p$ value $<0.001$ compared to the control. The experiment was performed independently at least three repeats. $\mathrm{E}$. Validation of the expression of VEGF in RPE cells treated with $3 \mu \mathrm{M}$ chrysin or $25 \mu \mathrm{M}$ A2E under photosensitization by RT-qPCR . ** indicates $p$ value $<0.01$, $\star \star \star$ indicates $p$ value $<0.001$, $\star \star \star \star$ indicates $p$ value $<0.0001$ compared to the control. The experiment was performed independently at least three repeats. F. Validation of the expression of the pro-inflammatory IL6 in RPE cells treated with $3 \mu \mathrm{M}$ chrysin or $25 \mu \mathrm{M}$ A2E under photosensitization by RT-qPCR. ** indicates $p$ value $<0.01$ compared to the control. The experiment was performed independently at least three repeats. 


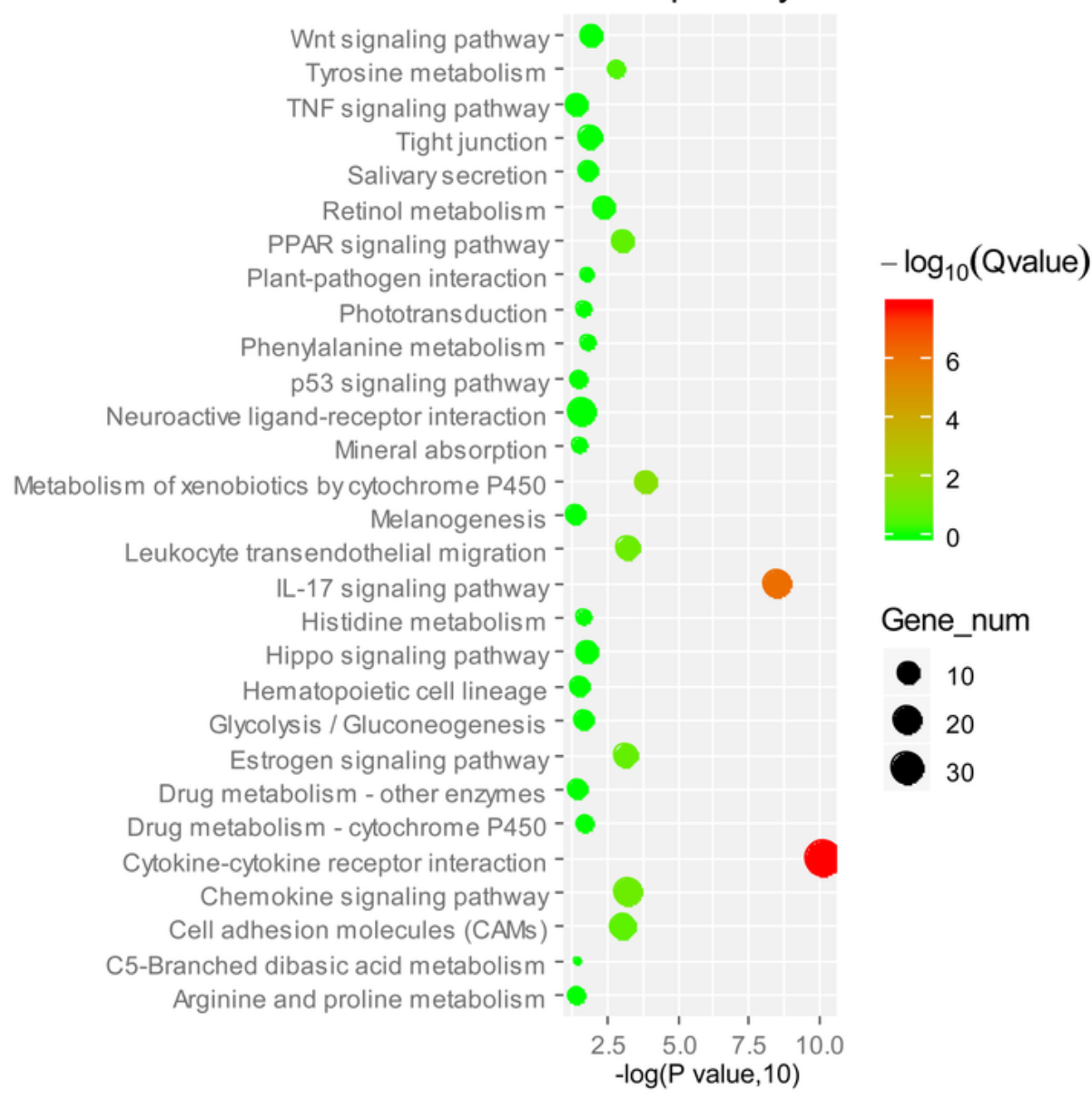

B

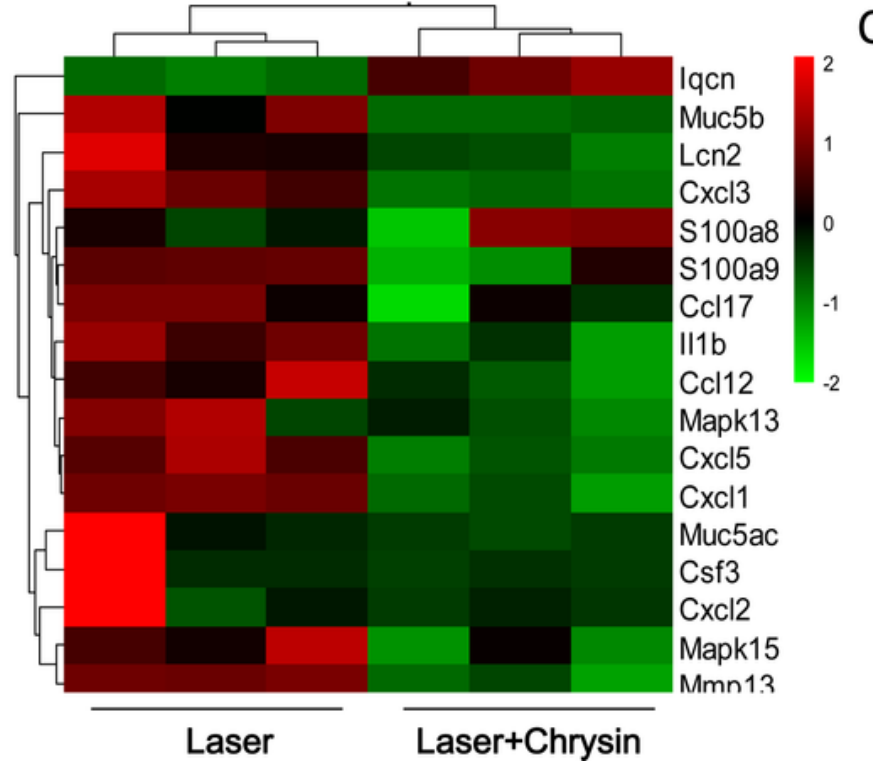

C

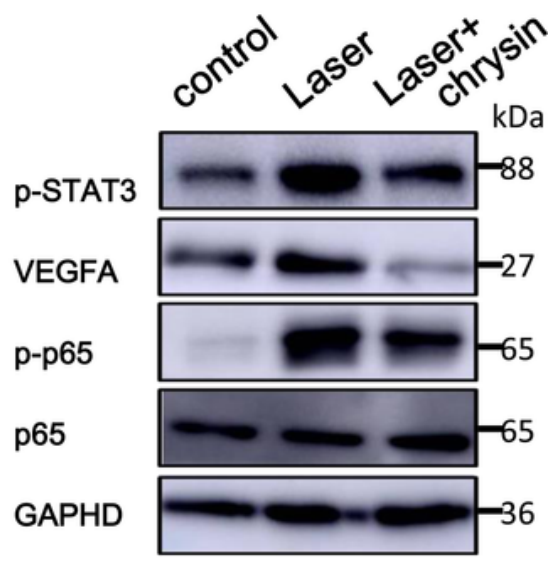

Figure 5

Chrysin suppressed inflammation in choroidal-RPE complex after laser treated through down-regulation the expression of p-STAT3 A. KEGG pathway analysis showing significantly changed genes in choroidalRPE complex after laser treated with chrysin treatment. B. Heat map showing genes related to IL-17 signaling pathway. C. Western blot showing p-STAT3, VEGFA, p65 and p-p65 proteins in choroidal-RPE complex after laser-treated with or without chrysin administered. 
A

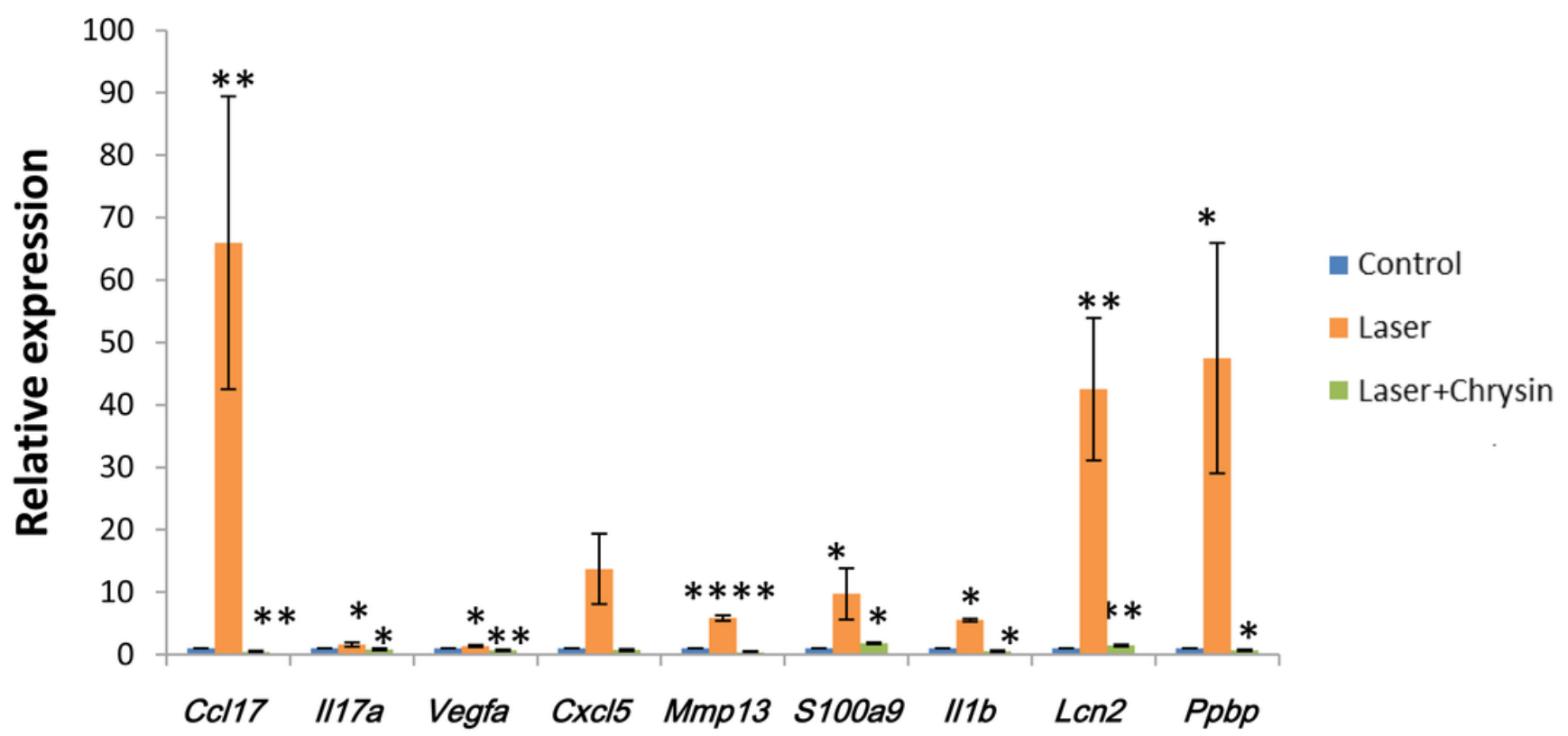

B

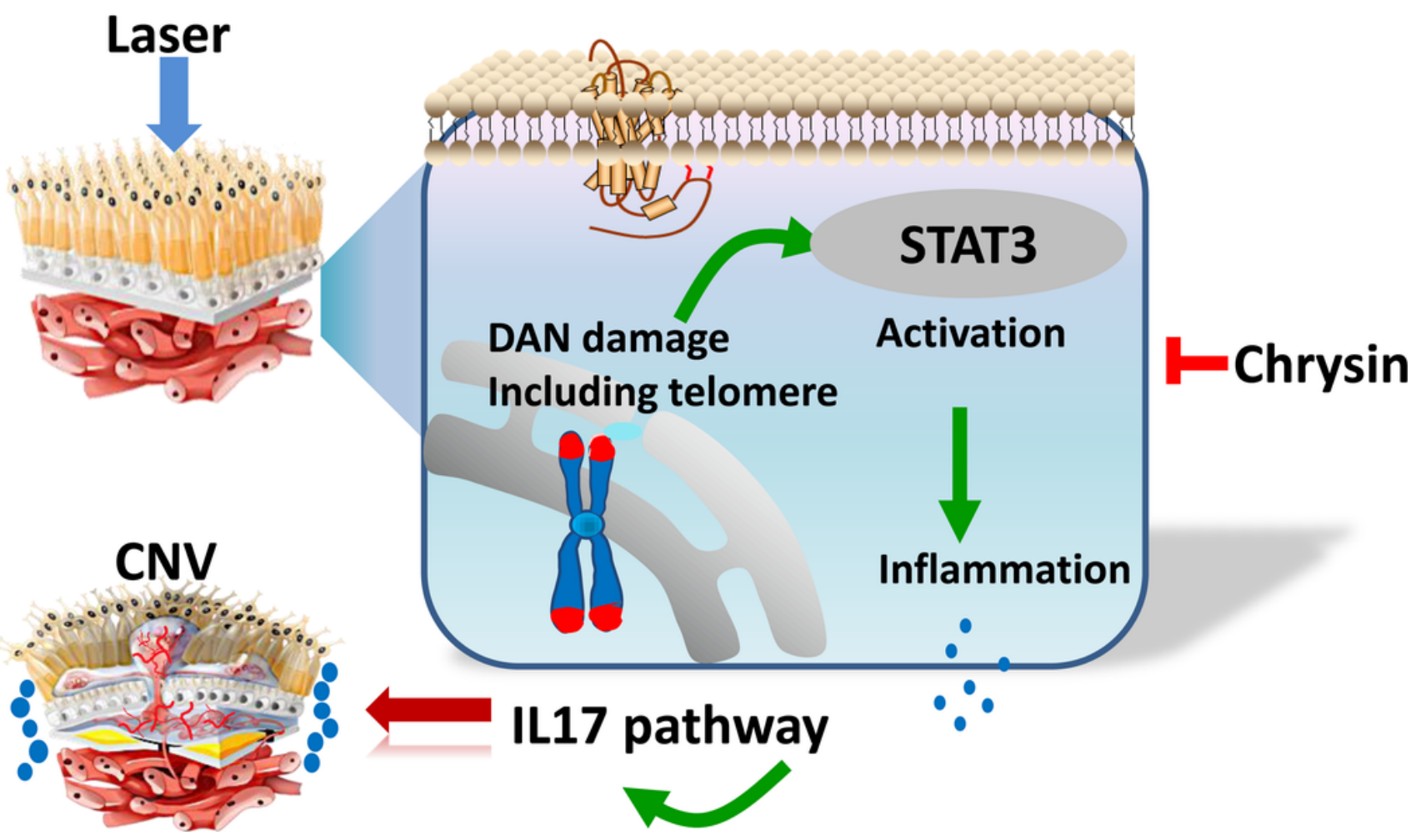

Figure 6

A paradigm: the mechanism of Chrysin alleviate laser-induce CNV. A. Validation of the expression of the pro-inflammatory genes in choroidal-RPE complex after laser treated with or without chrysin administered

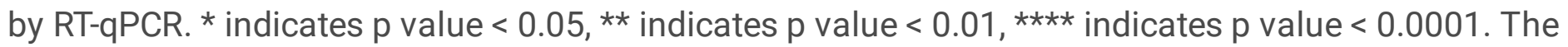
experiment was performed independently at least three repeats. B. A cartoon illustrating chrysin alleviating DNA damage to suppresses stress-induced inflammation in laser-induced choiral neovascularization. 


\section{Supplementary Files}

This is a list of supplementary files associated with this preprint. Click to download.

- additionalfile.doc 